\title{
A preliminary study of Liu Kang's palette and the discovery and interpretation of hidden paint layers
}

\author{
Damian Lizun* ${ }^{*}$
}

\begin{abstract}
This paper presents an overview of the results from the ongoing study on the materials and painting technique of the pioneering Singapore artist_Liu Kang. The paintings Zuo La Lu and Nude, which represent two of Liu Kang's early and distinct artistic phases_-Paris and Shanghai-were investigated for the first time using a combination of non- and micro-invasive techniques. The aim of this study was to identify the main pigments used by the artist and to add to the existing research on the artist's painting methods. The results show that the majority of pigments used in both paintings are similar and include Prussian blue, ultramarine, viridian, strontium yellow, chrome yellow, cadmium yellow, iron oxides, lead, zinc and barium whites, bone black and organic red. Particularly interesting is the predominance of lead white in Zuo La Lu and zinc white in Nude. A comparison of the ground layers also indicates the presence of a lead white admixture in Zuo La Lu while its absence in Nude may point to a characteristic difference between two artistic phases, possibly determined by the availability of materials. The imaging methods revealed hidden compositions: the view of a canal house behind Zuo La Lu, and a mystery outdoor view behind Nude. Although these investigative methods permitted some visualisation of the discarded compositions, it remains difficult to determine their details.
\end{abstract}

Keywords: Liu Kang, IRFC, MA-XRF, SEM-EDS, Pigment identification, Hidden painting

\section{Introduction}

Liu Kang was born in Yongchun, Fujian province, China, in 1911. He graduated from Xinhua Arts Academy in Shanghai in 1928. He stayed in Paris from 1928 to 1933, during which time he went on painting trips across Europe to assimilate the artistic essence of the Western masters. In 1933, he taught at the Shanghai Academy of Fine Art. He moved to Malaya in 1937 when the Sino-Japanese War broke out, and moved to Singapore in 1942. Liu Kang was active as an artist, educator and cultural commentator for about 60 years in Singapore. When he died in 2004, he was regarded as a pioneering

*Correspondence: damian_lizun@nhb.gov.sg

Heritage Conservation Centre (National Heritage Board), 32 Jurong Port Rd, Singapore 619104, Republic of Singapore
Singapore artist who had profoundly influenced generations of Singapore artists [1].

During his formative years in Paris, Liu Kang formulated modernist art concepts before he found his own approach to painting, influenced by Impressionist, PostImpressionist and Fauvist styles [2]. In an essay from 1980, Liu Kang made a reference to his stay in Paris: "As for myself, I have loved Vincent van Gogh and Paul Gauguin, and have also been infatuated with Henri Matisse. They have inclined me to adopt an optimistic and openminded approach [3]."

In an 1981 interview, he said: "One of the first things I saw when I arrived in Paris was the 60th-anniversary exhibition works by Matisse. The impact was powerful and lasting [4]."
Springer Open

(c) The Author(s) 2020. This article is licensed under a Creative Commons Attribution 4.0 International License, which permits use, sharing, adaptation, distribution and reproduction in any medium or format, as long as you give appropriate credit to the original author(s) and the source, provide a link to the Creative Commons licence, and indicate if changes were made. The images or other third party material in this article are included in the article's Creative Commons licence, unless indicated otherwise in a credit line to the material. If material is not included in the article's Creative Commons licence and your intended use is not permitted by statutory regulation or exceeds the permitted use, you will need to obtain permission directly from the copyright holder. To view a copy of this licence, visit http://creativeco mmons.org/licenses/by/4.0/. The Creative Commons Public Domain Dedication waiver (http://creativecommons.org/publicdomain/ zero/1.0/) applies to the data made available in this article, unless otherwise stated in a credit line to the data. 
Liu Kang's early explorations met with some success and his works were exhibited at Salon d'Automne in 1930 and 1931.

After returning to China, Liu Kang taught Western art at the Shanghai Academy of Fine Art and he was also at the centre of the Chinese modern art movement. He felt a strong need to search for and develop his own manner of painting, one that would bear the mark of his Chinese ethnicity. He combined Chinese ink technique with the colourful tones of Post-Impressionist works. Bands of bright, raw colours and quick, bold strokes characterised his works from that time onwards. The use of dark lines to delineate objects also became a dominant feature in his work [2].

Although there is an extensive literature on Liu Kang's works, none of these discussions included technical examination. Two paintings from the National Gallery Singapore, Zuo La Lu (1930) and Nude (1936), are amongst very few works from Liu Kang's Paris and Shanghai periods that have survived the Second World War. They exemplify the artist's early explorations of the Western painting style and his attempts at bridging East and West.

Zuo $\mathrm{La} \mathrm{Lu}$ is an oil-on-canvas painting measuring $46 \times 55 \mathrm{~cm}$ (Fig. 1). It is an outdoor scene depicting a townhouse behind a wall and some shrubs at Emile Zola Street. The palette of colours is characterised by different hues of blue, brown and green. Although the painting style is expressive, it betrays some attention to detail in the characterisation of the house.

Nude is a studio work painted in oils on a canvas measuring $46 \times 54.5 \mathrm{~cm}$ (Fig. 2). The painting shows a female

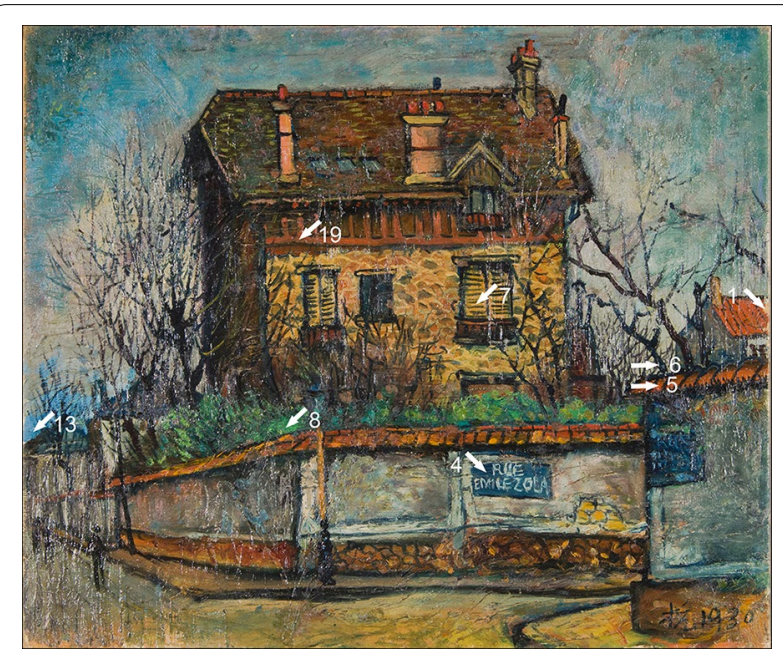

Fig. 1 Liu Kang, Zuo La Lu, 1930, oil on canvas, $46 \times 55 \mathrm{~cm}$. Collection of National Gallery Singapore. Image courtesy of National Heritage Board. White arrows indicate sampling areas

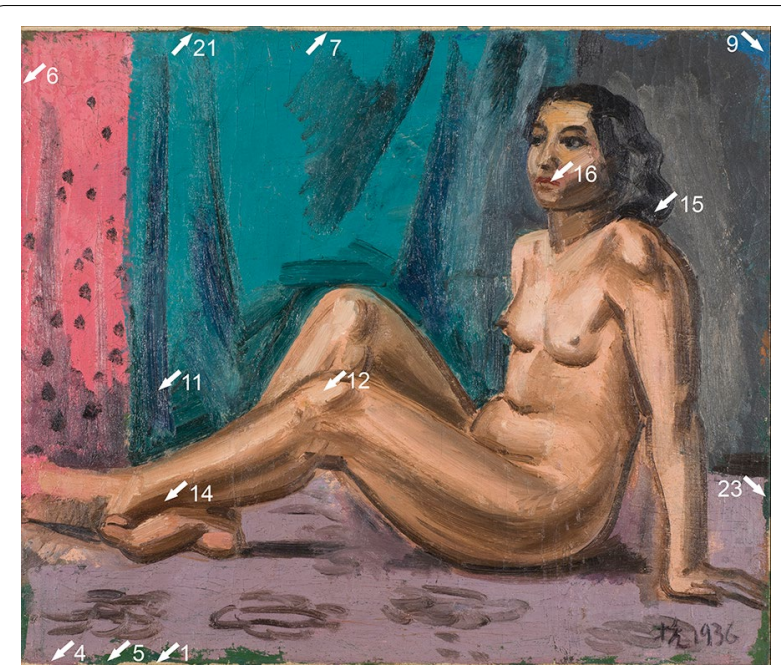

Fig. 2 Liu Kang, Nude, 1936, oil on canvas, $46 \times 54.5 \mathrm{~cm}$. Gift of the artist's family. Collection of National Gallery Singapore. Image courtesy of National Heritage Board. White arrows indicate sampling areas

model sitting in front of a simple backdrop. The colour block division of the background hints at the influence of the Post-Impressionists. The use of a broad brown line around the model's body betrays the influence of Chinese ink painting, a style that would later become Liu Kang's trademark [5]. This rapidly executed painting reveals the decisive use of a few strong colours.

As these two works represent different dates, genres and painting methods, they were selected to study the artist's painting materials. The paintings were investigated for the first time using a combination of in situ analytical non-invasive methods, and the results guided further micro-invasive techniques to characterise the pigments in detail.

\section{Methods}

\section{Technical photography}

High-resolution technical photography was conducted according to the workflow proposed by Cosentino [6-8]. A Nikon D90 DSLR modified camera with a sensitivity of between about 360 and $1100 \mathrm{~nm}$ was used with following filter sets:

a. X-Nite CC1 coupled with B+W 415, for visible, raking, transmitted light photography and ultraviolet fluorescence (UVF) photography at $365 \mathrm{~nm}$;

b. Heliopan RG1000, for near-infrared (NIR) photography at $1000 \mathrm{~nm}$ with an additional aim of infrared false-colour imaging (IRFC);

c. Andrea "U" MK II for reflected ultraviolet photography (UVR). The lighting system was composed of 
Table 1 Pigments detected in the painting Zuo La Lu by SEM-EDS and PLM

\begin{tabular}{|c|c|c|c|c|c|}
\hline Samples & $\begin{array}{l}\text { Colour/ } \\
\text { stratigraphy } \\
\text { layer }\end{array}$ & Location & $\begin{array}{l}\text { SEM-EDS detected } \\
\text { elements }^{\text {a }}\end{array}$ & $\begin{array}{l}\text { SEM-EDS possible } \\
\text { assignment }\end{array}$ & PLM identification \\
\hline 1 & White & Ground layer & $\mathbf{O}, \mathbf{C}, \mathbf{C a}, \mathrm{Pb}, \mathrm{Zn}, \mathrm{Na},(\mathrm{Si}, \mathrm{Al}, \mathrm{Mg})$ & $\begin{array}{l}\text { Calcium carbonate, lead white, } \\
\text { zinc white }\end{array}$ & $\begin{array}{l}\text { Calcium carbonate, lead white, } \\
\text { zinc white }\end{array}$ \\
\hline 4 & Blue & Street name sign & $\begin{array}{l}\mathrm{Pb}, \mathbf{C}, \mathbf{O}, \mathrm{Ca}, \mathrm{Ba},(\mathrm{Fe}, \mathrm{Na}, \mathrm{Al}, \mathrm{Si} \\
\quad \mathrm{Mg})\end{array}$ & $\begin{array}{l}\text { Prussian blue, lead white, } \\
\text { barium white }\end{array}$ & Prussian blue, lead white \\
\hline 13 & Blue & Sky & $\mathbf{P b}, \mathbf{C}, \mathbf{O}, \mathbf{C a},(\mathrm{Zn}, \mathrm{Mg}, \mathrm{Na}, \mathrm{Si}, \mathrm{Al})$ & $\begin{array}{l}\text { Prussian blue, ultramarine, lead } \\
\text { white, zinc white }\end{array}$ & $\begin{array}{l}\text { Prussian blue, ultramarine, lead } \\
\text { white, zinc white }\end{array}$ \\
\hline \multirow[t]{3}{*}{8} & Green & Shrubs above the fence & $\begin{array}{l}\text { C, } \mathbf{O}, \mathrm{Cr}, \mathrm{Cd}, \mathrm{S}, \mathrm{Pb}, \mathrm{Ba}, \mathrm{Al}, \mathrm{Zn} \\
\quad(\mathrm{Ca}, \mathrm{Fe}, \mathrm{Mg}, \mathrm{Na}, \mathrm{Cl}, \mathrm{Si})\end{array}$ & $\begin{array}{l}\text { Ultramarine, viridian, Prussian } \\
\text { blue, lead white, cadmium } \\
\text { yellow or light cadmium yel- } \\
\text { low, zinc white, barium white } \\
\text { or lithopone }\end{array}$ & $\begin{array}{l}\text { Ultramarine, viridian, Prussian } \\
\text { blue, lead white, cadmium } \\
\text { yellow }\end{array}$ \\
\hline & Yellow cluster & & $\begin{array}{l}\text { O, Pb, C, Ca, Cr, S, (Al, Ba, Zn, } \\
\quad \text { Mg, Si) }\end{array}$ & $\begin{array}{l}\text { Chrome-containing yellow(s) } \\
\text { and green(s) }\end{array}$ & \\
\hline & Green cluster & & $\begin{array}{l}\text { O, C, Pb, Ca, Cr, Ba, (S, Al, Cd, } \\
\quad \mathrm{Fe}, \mathrm{Si})\end{array}$ & $\begin{array}{l}\text { Chrome-containing yellow(s) } \\
\text { and green(s), traces of cad- } \\
\text { mium yellow }\end{array}$ & \\
\hline 7 & Yellow & Wooden blinds & $\begin{array}{l}\text { O, C, Pb, Si, Fe, Al, Ca, Sr, As, } \\
\quad(\mathrm{Ba}, \mathrm{K}, \mathrm{Cr}, \mathrm{P}, \mathrm{Na}, \mathrm{Mg})\end{array}$ & $\begin{array}{l}\text { Yellow iron oxide, chrome yel- } \\
\text { low, barium white, gypsum, } \\
\text { kaolin, strontium yellow, } \\
\text { possible other chrome- } \\
\text { containing yellow(s) }\end{array}$ & $\begin{array}{l}\text { Yellow iron oxide, chrome yel- } \\
\text { low, strontium yellow }\end{array}$ \\
\hline 19 & Brown & House wall & $\begin{array}{l}\text { C, Pb, O, Ca, Fe, Si, Al, As, (Ba, P, } \\
\quad \mathrm{Na}, \mathrm{Sr}, \mathrm{Zn}, \mathrm{Cr}, \mathrm{Mg})\end{array}$ & $\begin{array}{l}\text { Brown iron oxide, strontium } \\
\text { yellow, bone black }\end{array}$ & $\begin{array}{l}\text { Brown iron oxide, strontium } \\
\text { yellow }\end{array}$ \\
\hline 5 & Red & $\begin{array}{l}\text { Tile from the roof of the } \\
\text { smaller house }\end{array}$ & $\begin{array}{l}\text { O, C, Pb, Ca, Cr, P, Al, Fe, (Si, As, } \\
\quad \mathrm{Zn}, \mathrm{Na}, \mathrm{Cl}, \mathrm{Ba}, \mathrm{Mg})\end{array}$ & $\begin{array}{l}\text { Red iron oxide, chrome yellow, } \\
\text { possible other chrome- } \\
\text { containing yellow(s) }\end{array}$ & Red iron oxide, chrome yellow \\
\hline 6 & Black & Tree branch & $\begin{array}{l}\text { O, Pb, C, Fe, Ba, Ca, S, Na, Si, (K, } \\
\quad \text { Al, P, Zn) }\end{array}$ & $\begin{array}{l}\text { Prussian blue, bone black, lead } \\
\text { white, barium white }\end{array}$ & $\begin{array}{l}\text { Prussian blue, bone black, lead } \\
\text { white }\end{array}$ \\
\hline
\end{tabular}

a Major elements are given in bold, minor elements in plain type and trace elements in brackets

two $500 \mathrm{~W}$ halogen lamps as an illumination source for visible, raking, transmitted light and NIR photography. Two lamps equipped with eight $40 \mathrm{~W} 365 \mathrm{~nm}$ UV fluorescence tubes were used for UVF and UVR photography.

The camera was calibrated with the X-Rite ColorChecker Passport. The American Institute of Conservation Photo Documentation Target (AIC PhD Target) was used for images white balance and exposure control. The images were further processed by Adobe Photoshop CC in accordance with the standards described by the American Institute of Conservation [9].

\section{Reflectance transformation imaging}

Reflectance transformation imaging (RTI) was carried out according to the workflow proposed by the Cultural Heritage Imaging [10]. The images were processed using Adobe Photoshop, followed by RTIBuilder and RTIViewer software, proposed by the Cultural Heritage Imaging $[11,12]$.

\section{$\mathrm{X}$-ray radiography}

The digital X-ray radiography (XRR) was carried out at the radiology department of the Singapore General Hospital using a Siemens Ysio Max Digital X-ray System with a $35 \times 43 \mathrm{~cm}$ detector that delivers high-pixel resolution images (over 7 million pixels). The X-ray tube operated at $40 \mathrm{kV}$ and $0.5-2 \mathrm{mAs}$. The images were first processed with an X-ray medical imaging software, iQ-LITE, then exported to Adobe Photoshop CC for final alignment and merging.

\section{Macro X-ray fluorescence}

The elemental mapping of the entire surface of the paintings was conducted with a macro X-ray fluorescence (MA-XRF) scanner, the M6 Jetstream from Bruker Nano $\mathrm{GmbH}$. The instrument consists of a $30 \mathrm{~W}$ Rh-target microfocus X-ray tube, with a maximum voltage of $50 \mathrm{kV}$ and a maximum current of $600 \mu \mathrm{A}$. The instrument is equipped with a $30 \mathrm{~mm}^{2}$ active area XFlash Silicon Drift Detector with an energy resolution of $<145 \mathrm{eV}$ for $\mathrm{Mn}$ $\mathrm{K} \alpha$. A detector is mounted on an $\mathrm{X}-\mathrm{Y}-\mathrm{Z}$ motorised stage 


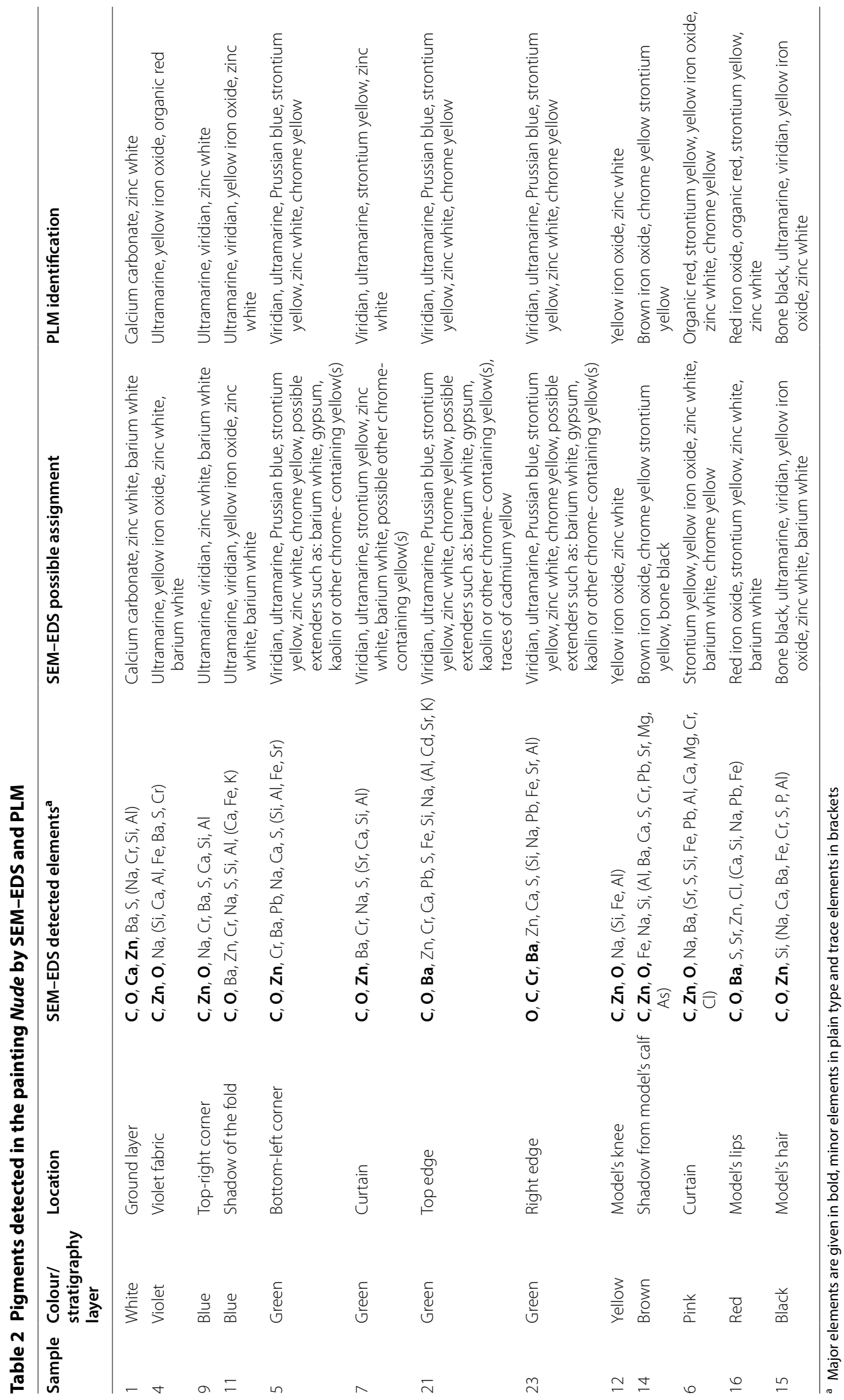



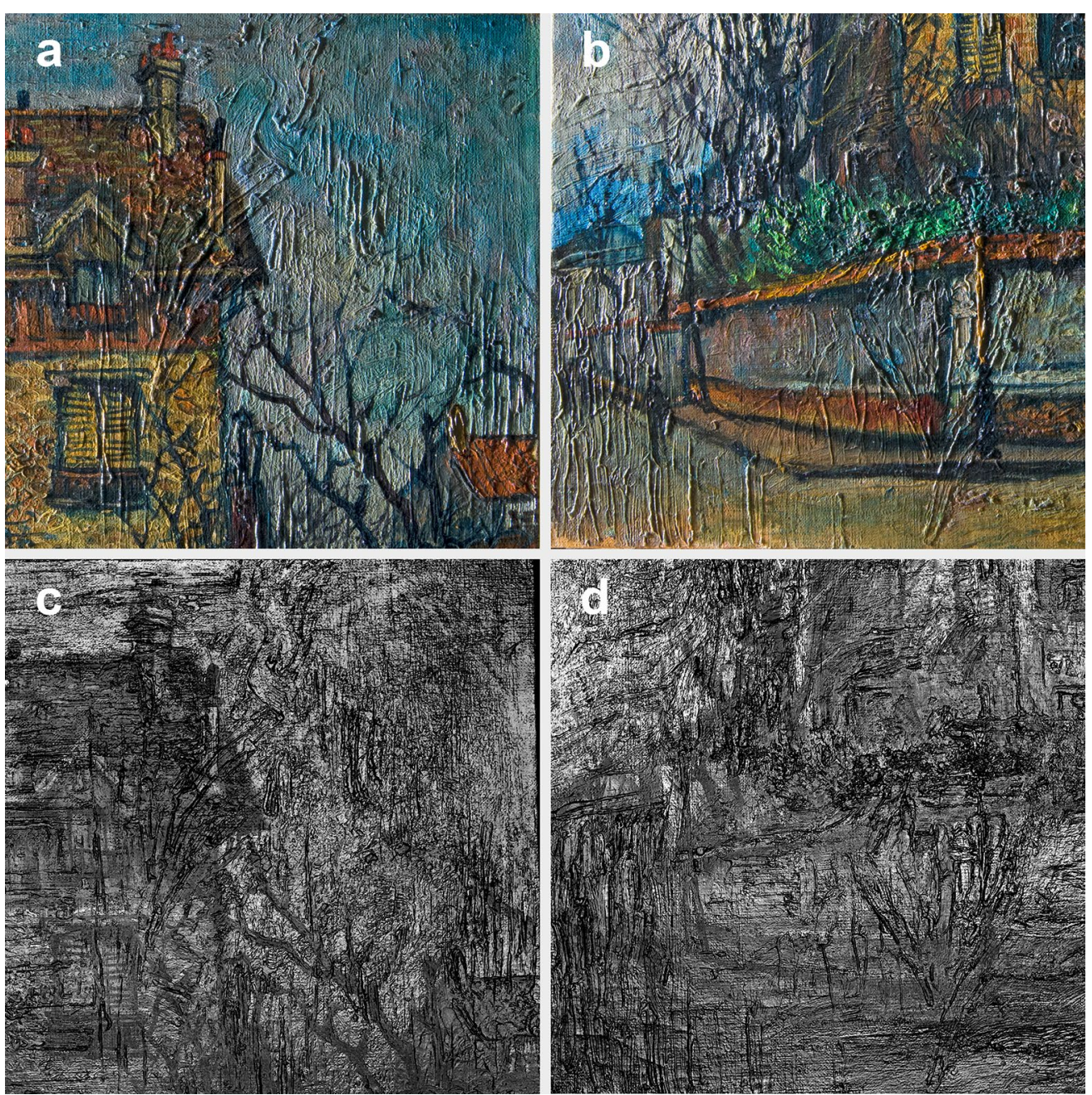

Fig. 3 Details of Zuo La Lu: $\mathbf{a}$, b photographed in raking light; $\mathbf{c}$, d photographed by RTI technique. Both imaging techniques reveal texture details corresponding to the earlier painted composition

with a maximum scanning range of $80 \times 60 \times 9 \mathrm{~cm}$. The instrument offers an adjustable spot size from 100 to approximately $500 \mu \mathrm{m}$ [13]. The elemental distribution maps of the paintings were collected with a dwell time of $10 \mathrm{~ms} /$ pixel, a pixel size of $300 \mu \mathrm{m}$ and an anode current of $599 \mu \mathrm{A}$. The acquired spectra were collected and analysed using Bruker's M6 software, which allows the elemental distribution maps to be produced.

\section{Optical microscopy and polarized light microscopy}

Optical microscopy (OM) of the samples was carried out in visible and ultraviolet reflected light on the Leica DMRX polarized microscope at magnifications of $\times 40$, $\times 100$ and $\times 200$ equipped with Leica DFC295 digital camera. Polarized light microscopy (PLM) was carried out using the methodology developed by Peter and Ann Mactaggart [14].

\section{Scanning electron microscope with energy dispersive spectroscopy}

All samples (powdered paint samples and cross-section) were mounted on high purity carbon tapes and examined with a scanning electron microscope (SEM) Hitachi SU5000 SEM, coupled with energy dispersive X-ray spectroscopy (EDS), Bruker XFlash 6|60. In SEM, the backscattered electron mode was used in $60 \mathrm{~Pa}$ vacuum, with $20 \mathrm{kV}$ beam acceleration, at 50-60 intensity spot and a working distance of $10 \mathrm{~mm}$. The distribution of chemical elements was mapped using Qantax Esprit processing software. 

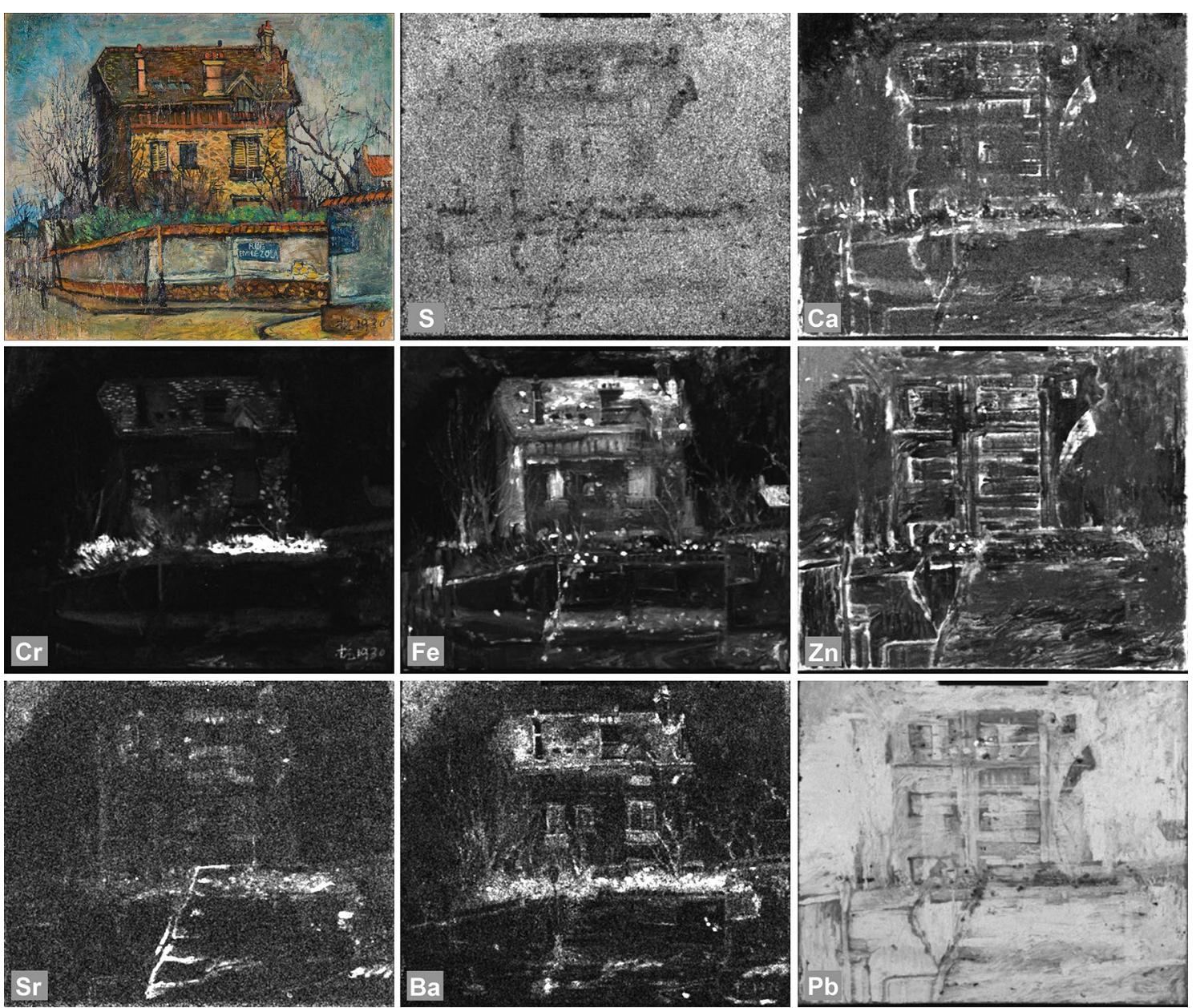

Fig. 4 Visible light image and MA-XRF maps of Zuo La Lu showing the distribution of the detected elements. The greyscale corresponds to the intensity of the signal of each element; white equals high intensity, black means low intensity. Distribution maps of $\mathrm{Ca}, \mathrm{Zn}$ and $\mathrm{Pb}$ reveal the hidden composition rotated at $90^{\circ}$ anticlockwise

\section{Samples}

Based on the preliminary non-invasive investigation, eight micro-samples from $\mathrm{Zuo} \mathrm{La} \mathrm{Lu}$ and thirteen samples from Nude were analysed for this study.

Samples of the paint for cross-section structure observation and analysis were embedded in a fast-curing acrylic resin ClaroCit (supplied by Struers) and polished with abrasives down to grade 4000 . The mounting medium for PLM pigment dispersion was Cargille Meltmount $\mathrm{nD}=1.662$.

A summary of the identified materials is given in Tables 1 and 2.

\section{Results and discussion}

\section{Hidden painting beneath Zuo La Lu}

The raking light and RTI examination revealed the presence of impastos that do not correspond to the present paint scheme. The impastos was evident in the areas of sky, house, fence and road in the bottom-left corner of the painting (Fig. 3). Subsequent MA-XRF scanning revealed the underlying view of a canal house painted in vertical orientation (Fig. 4). The hidden composition is visualised in the $\mathrm{Pb}, \mathrm{Zn}$ and $\mathrm{Ca}$ distribution maps. Interestingly, the $\mathrm{Zn}$ and $\mathrm{Ca}$ maps appear as a negative image of the $\mathrm{Pb}$ distribution, indicating that the $\mathrm{Zn}$ - and $\mathrm{Ca}$-signals source is the ground layer blocked locally by the $\mathrm{Pb}$-containing paint of an underlying painting. This observation finds confirmation in the upper part of the underlying painting where what was probably the sky colour has a high concentration of $\mathrm{Pb}$-containing pigment corresponding to the heavy impastos imaged in XRR. The XRR additionally revealed expressive brushstrokes that are much more visible than in the RTI, suggesting an attempt to imitate van Gogh's style (Fig. 5). The primary source of contrast in the radiographic image was the thickness variations of paint layer which 

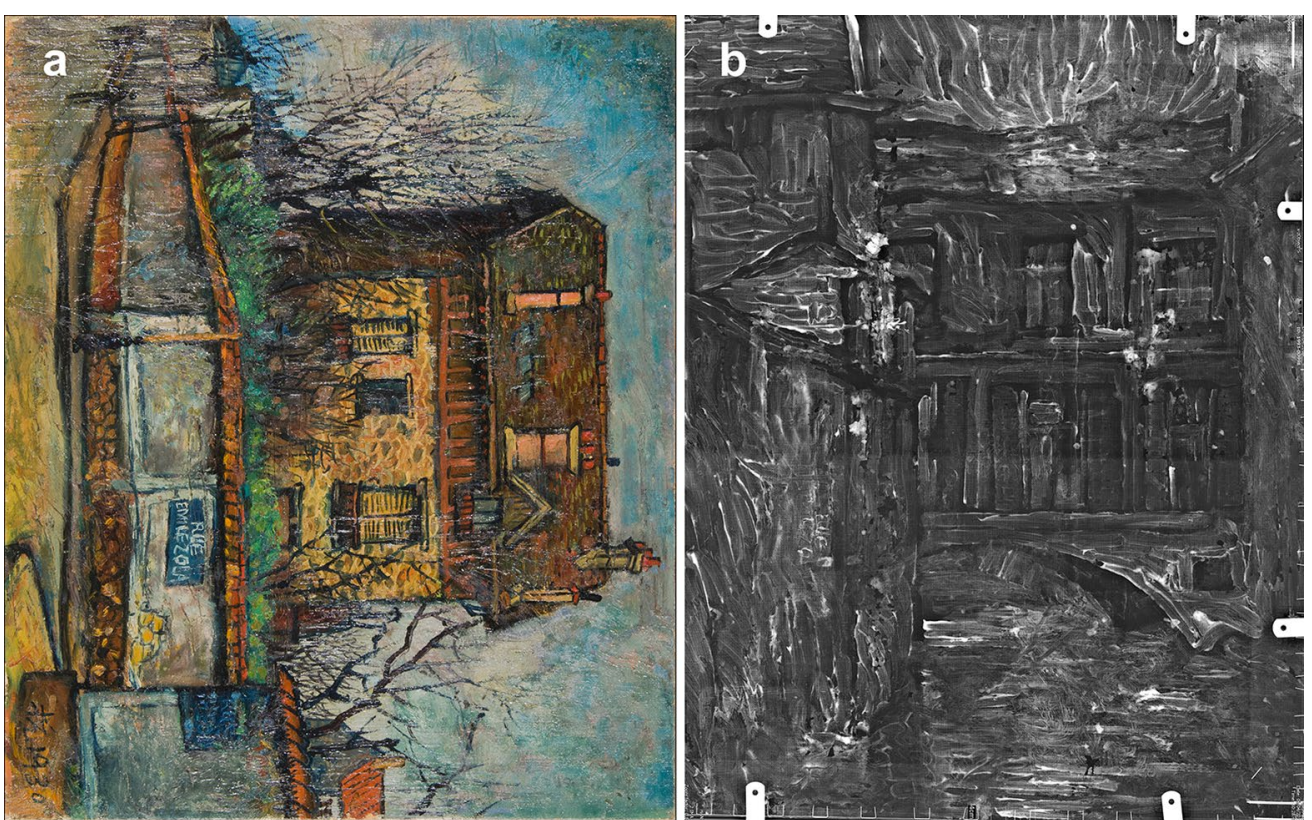

Fig. 5 Visible light (a) and XRR image (b) of Zuo La Lu rotated at $90^{\circ}$ clockwise. XRR reveals the hidden painting of canal house

is rich in heavy metal, applied over a thinner ground of a similar chemical composition [15].

\section{Hidden painting beneath Nude}

A visual examination of the painted edges of Nude revealed the presence of green and blue paint to be unrelated to the final image (Fig. 6). An examination of the painting's surface with the raking light and RTI pointed out the impastos and other expression effects that do not correlate to the final composition. The underlying paint layer is characterised by marks probably achieved by scratching into wet paint with a palette knife, the end of a brush handle or any sharp tool. In the area of the feet, the marks have a form of crossed lines, like a net or garden fence. In the area of the model's left calf, small circles were scratched. Additionally, thick impastos were noticed in the area of the breast and the adjacent green background (Fig. 7). The XRR of Nude remains inconclusive; however, it suggests that the unveiled composition was painted in the horizontal orientation and that there might be shrubs or other greenery on the left side of the painting, where the scratching marks were noticed (Fig. 8). Similarly to $\mathrm{Zuo} \mathrm{La} L u$, the thickness variations in the hidden paint layer play a role in the absorption of $\mathrm{X}$-rays and rendering the $\mathrm{X}$-ray image. This observation finds confirmation in the MA-XRF distribution map of $\mathrm{Pb}$ (Fig. 9) compared with XRR. A strong Pb-signal from the underlying composition corresponds to the impastos recorded with RTI and XRR. However, the Pb-signal from the model's face does not correlate with the thick brushwork recoded with raking light photography, RTI and XRR (Fig. 10), suggesting that the Pb-containing paint was applied at an earlier stage of the painting and covered with a thick application of a $\mathrm{Zn}$-containing paint. Consequently, this assumption is supported by the $\mathrm{Zn}$ map, which appears as a negative image of the $\mathrm{Pb}$ distribution in the area of model's face (Fig. 9).

The underlying composition partially visible in the $\mathrm{Pb}$ distribution map is also not sufficiently recorded in the distribution maps for other elements present. However, some paint fragments along the painting turnover edges provide limited information about the pigment composition and will be discussed in the next chapter.

\section{Ground layer}

SEM-EDS measurements combined with PLM observations indicated that the composition of the ground layer in both paintings differs. In $Z u o L a L u$, the ground layer probably consists of a mixture of calcium carbonate (coccoliths were visible in normal and polarized light), lead white (particles appear greenish and show hexagonal angles in normal light), and zinc white (small particles appear yellow in normal light). The ground layer in Nude probably involves calcium carbonate with the addition of zinc white and barium white based on the co-location of $\mathrm{Ba}$ and $\mathrm{S}$ in the sample examined with SEM-EDS.

\section{Blue and violet paints}

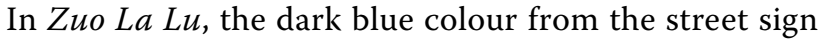
and light blue from the sky were analysed. An IRFC 

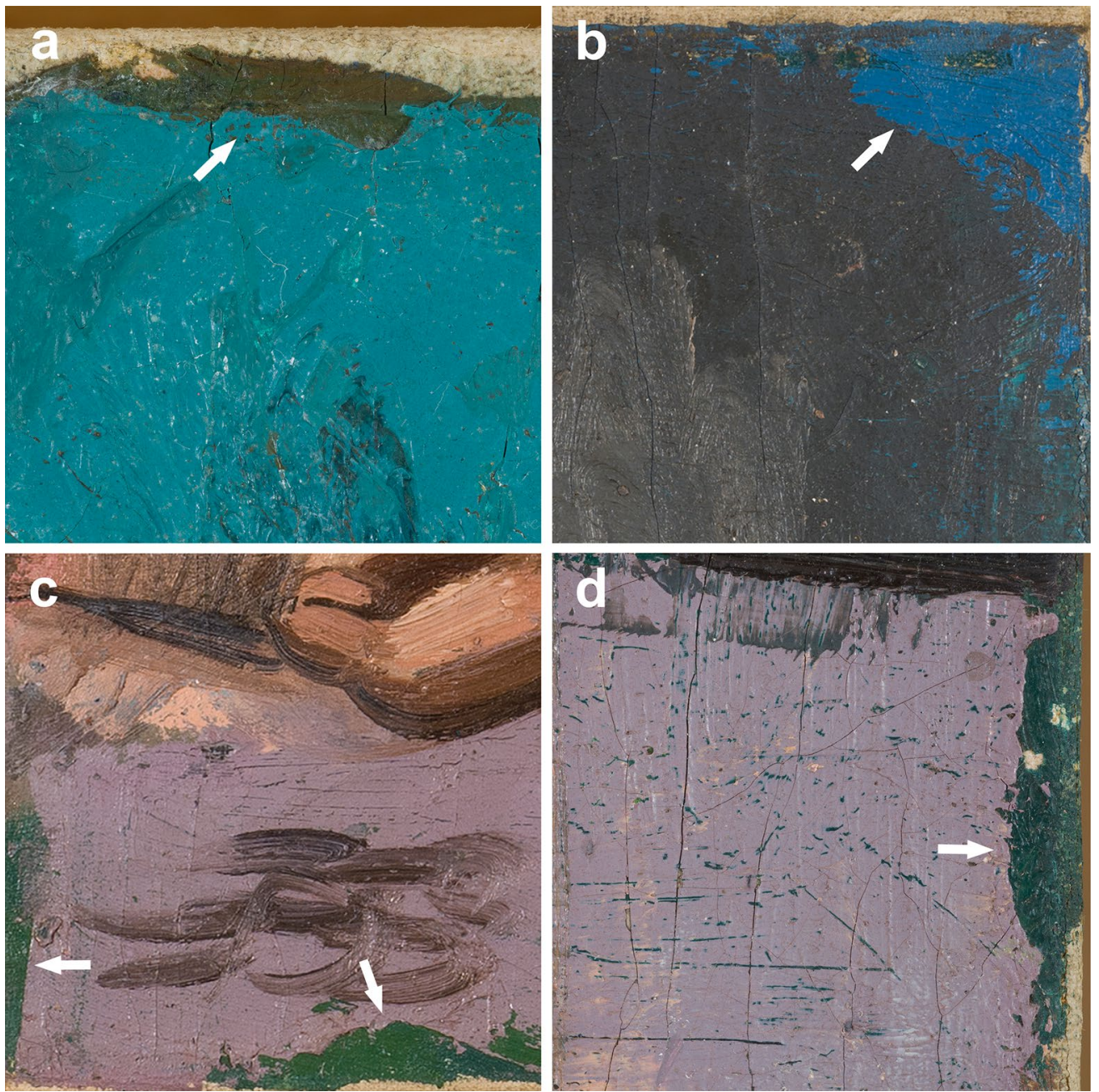

Fig. 6 Details of Nude showing paint fragments corresponding to the earlier painted composition: a green at the top edge; $\mathbf{b}$ blue at the top-right corner; c green at the bottom-left corner; $\mathbf{d}$ green at the right edge

(Fig. 11) was very effective, with preliminary indication that the painted areas contain Prussian blue. This pigment is known for its strong absorption of infrared; thus the blue street sign appears dark blue in IRFC imaging. Moreover, Prussian blue has very high tinting strength, so a low concentration of pigment is needed to achieve a blue shade. An MA-XRF scan of the area (Fig. 12) and a SEM-EDS analysis of the paint sample confirmed a small concentration of $\mathrm{Fe}$, which was further identified with PLM as Prussian blue (particles appear greenish with Chelsea filter) (Fig. 13). An SEM-EDS analysis also recorded a signal of $\mathrm{Pb}, \mathrm{Ca}$ and $\mathrm{Ba}$, suggesting the use of lead white, chalk and barium white in the paint mixture.

The blue sky was imaged violet in an IRFC (Fig. 11), suggesting the use of a complex paint mixture. The SEM-EDS recorded traces of elements characteristic for Prussian blue and ultramarine, confirmed with PLM (ultramarine particles appear red with Chelsea filter). The MA-XRF was not able to visualise ultramarine due to the low atomic number of the element content of this pigment; its concentration was below the detection limit of the instrument. The final result seems to be consistent with the IRFC imaging as the purple and dark blue representation of ultramarine and Prussian blue can produce violet when combined. The brighter tone of the blue sky was achieved by adding lead and zinc whites identified by SEM-EDS and PLM.

In Nude, a blue paint from top-right corner turns purple in the IRFC image (Fig. 14), suggesting the use of ultramarine or cobalt blue. MA-XRF detected a Cr-signal (Fig. 9), which could be related to the use of Cr-containing yellow or green pigment(s). SEMEDS combined with PLM allowed the identification 

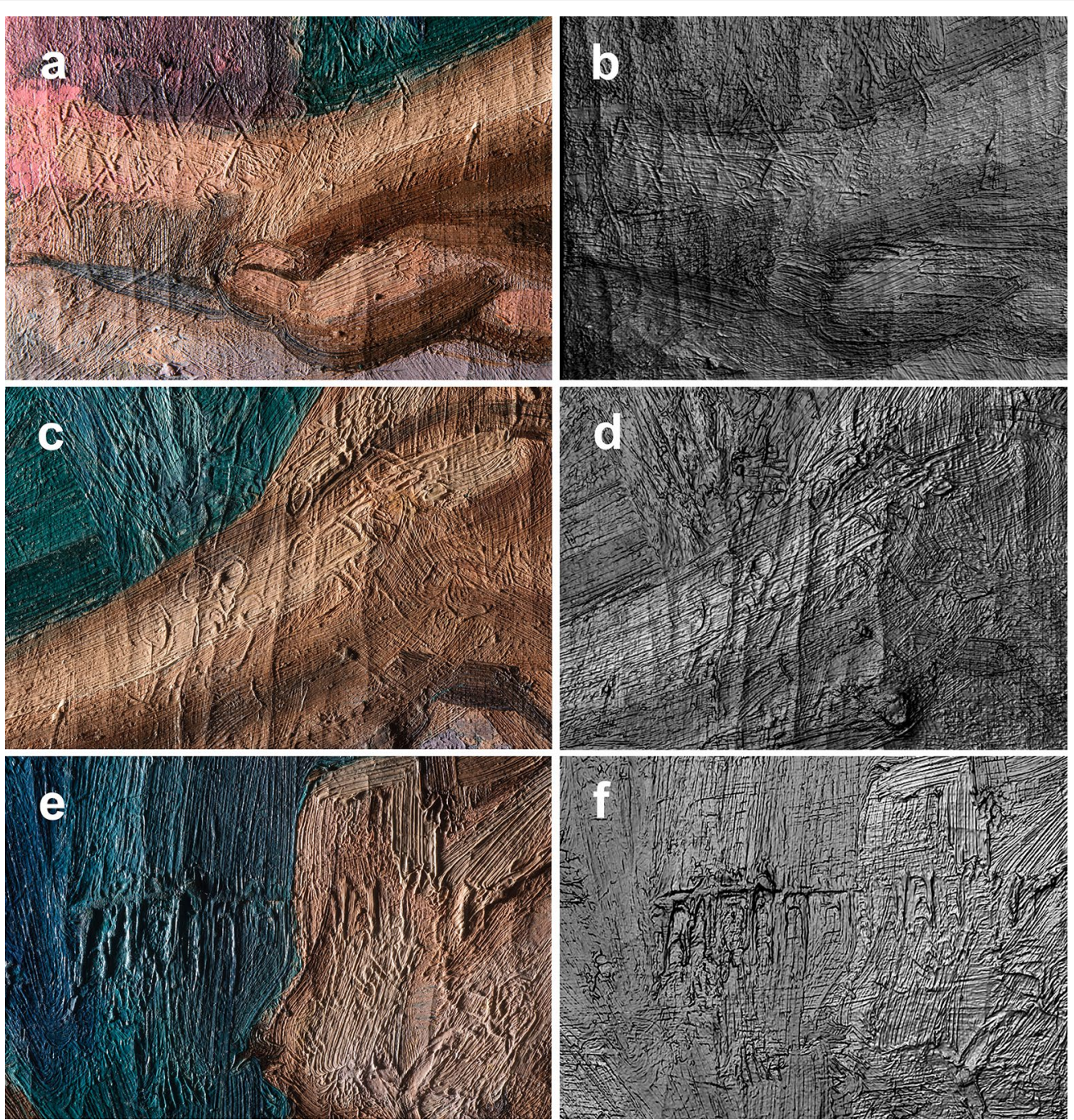

Fig. 7 Details of Nude: $\mathbf{a}, \mathbf{c}, \mathbf{e}$ photographed in raking light; $\mathbf{b}, \mathbf{d}, \mathbf{f}$ photographed employing RTI technique. Both imaging techniques reveal texture details corresponding to the earlier painted composition

of ultramarine with an admixture of viridian (the particles are large and rounded, with a rough surface, and appear warm grey with Chelsea filter). These findings correspond to the purple colour in the IRFC image of the area. The blue paint was brightened with the addition of zinc and barium whites based on the SEM-EDS co-location of Ba and S. The microscopic observation of the paint cross-section reveals that the blue paint was laid directly on the ground layer, thus suggesting that it may relate to the previous paint scheme (Fig. 15). Liu Kang, while creating the present painting, decided to retain this fragment of the previous work; therefore it was included in the study.

Based on the SEM-EDS and PLM analysis of the paint from the violet fabric in Nude, it is possible to conclude that the mixture contains ultramarine with yellow iron oxide-containing pigment and organic red. Iron oxide pigment was identified with PLM by anisotropic yellow and brown particles with high refractive index. Organic red can be distinguished from the other reds with PLM by its unique low refractive index; however, a full identification of the organic red pigment is needed. The presence of $\mathrm{Zn}$ and the analogous location of $\mathrm{Ba}$ to that of $\mathrm{S}$ may indicate the use of zinc white-identified with PLM and barium white extender-which could be assigned to an organic red [16].

In the same painting, the dark-blue shadows of the folds of the green background were painted mainly with a mixture of ultramarine, viridian, yellow iron oxide, zinc and barium whites. 


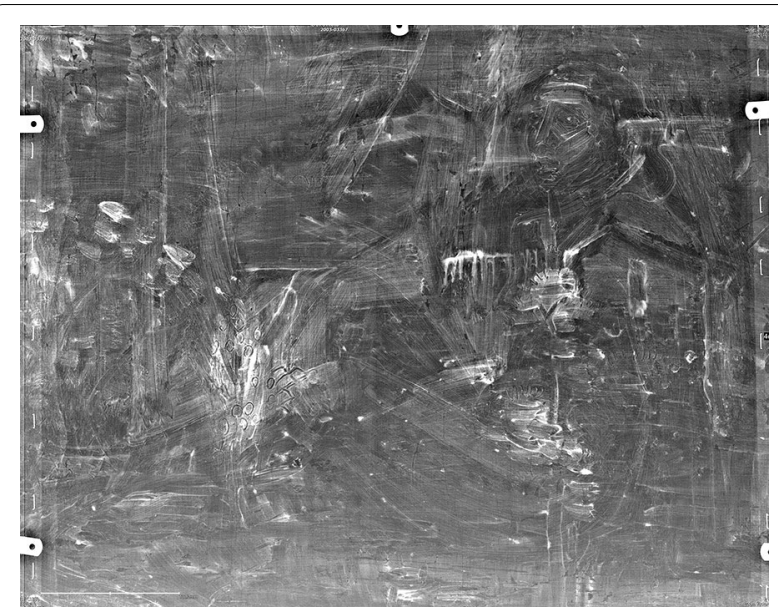

Fig. 8 The XRR image of Nude remains inconclusive; however, it suggests that the unveiled composition was painted in the horizontal orientation and that there might be shrubs or other greenery on the left side of the painting, where the scratching marks were noticed

\section{Green paints}

The green shrubs painted above the fence in Zuo La $L u$ are imaged in IRFC partially violet and purple, suggesting a complex paint mixture (Fig. 11). The MA-XRF recorded strong $\mathrm{Cr}$ - and $\mathrm{Ba}$-signals, which could suggest the presence of Cr-containing green and/or yellow pigments (Fig. 4). The SEM-EDS and PLM identified a mixture of viridian and ultramarine (both appear purple in the IRFC), Prussian blue (responsible for partial violet imaging in the IRFC), lead white and cadmium yellow. Cadmium yellow was characterised by strong Cd- and S-signals, recorded with SEM-EDS (Fig. 16) and PLM observation (yellow, anisotropic particles with high refractive index turn green in crossed polarized filters). The intensity of SEM-EDS peaks of Zn and Ba may suggest a presence of zinc and barium whites or lithopone but they also can be attributed to the light cadmium yellow commonly extended with barium white and called cadmopone [17]. Paint cross-section microphotography (Fig. 17) shows another layer beneath the top green that consists of clusters of not properly mixed yellow and green paints. The SEM-EDS analysis of the yellow (Fig. 18) and green (Fig. 19) clusters and elemental distribution maps (Fig. 20) of the entire sample indicate a strong $\mathrm{Pb}-, \mathrm{Ca}-$ and $\mathrm{Cr}$-signals, suggesting a presence of Cr-containing yellow and green pigments with possible extenders. Hermann Kühn and Mary Curran mention that chrome yellow may have extenders such as barium white, gypsum or kaolin [18], while calcium chromate was also used as an admixture [18]. Although pigments identified beneath the top layer of green paint provided some information about the paint mixture, it is unclear whether this layer is part of the current composition build-up or belongs to the underlying painting.

In Nude, the green curtain behind the model was visualised with MA-XRF distribution maps of $\mathrm{Cr}$, $\mathrm{Ba}, \mathrm{Sr}, \mathrm{S}$ and $\mathrm{Zn}$ (Fig. 9), while IRFC imaged the area in purple (Fig. 14). Although both results indicated a probable use of Cr-containing green and yellow pigments, a turquoise hue of the green paint suggested that blue could have been added as well. This observation was further confirmed by the identification of viridian and ultramarine with SEM-EDS and PLM (Fig. 21). The artist probably modified a green colour by adding strontium yellow (distinct large needles are visible in PLM) and brightened it with zinc and barium whites; however, strong Ba-, $\mathrm{Zn}$ - and $\mathrm{Cr}$-signals would also account for the presence of other Cr-containing yellow pigments, which were not detected with PLM but cannot be excluded [18].

Four fragments of green paint along the bottom, top, left and right edges of Nude are part of the hidden painting (Fig. 6). Liu Kang did not intend to cover the earlier artwork while painting Nude, therefore the green paint fragments are included in this study. The MA-XRF elemental distribution maps (Fig. 9) showed that these green paint fragments consist of several elements that could be made up of Cr-containing green and yellow pigments identified by SEM-EDS and PLM as viridian, strontium and chrome yellow (the particles between crossed polarized filters appear as tiny rods with high refractive index). The source of other elements like, $\mathrm{Al}, \mathrm{S}, \mathrm{Ca}$ and $\mathrm{Ba}$, is difficult to pinpoint as their presence may be due to a number of materials, such as extenders for chrome yellow [18]; although these additions were not identified with PLM, they cannot be excluded. Admixtures of ultramarine and Prussian blue were also identified with SEMEDS and PLM. The green paint sample from the right edge contains a very high concentration of $\mathrm{Cr}$, which was assigned to viridian with SEM-EDS and PLM. Thus, the elemental analyses are consistent with the IRFC image (Fig. 14), indicating that viridian and ultramarine are responsible for the purple appearance, and the admixture of Prussian blue contributes to the violet appearance. All fragments of green paint were brightened with zinc white, identified with SEM-EDS and PLM.

\section{Yellow and brown paints}

In $Z$ uo $L a L u$, different hues of yellow paint appear on the house wall, windows and road while brown was used for the roof and fence tiles. In Nude, yellow and brown were used for the flesh tones rendering and outlining the model's body. These parts of the paintings are imaged with different hues of yellow-green in the IRFC (Figs. 11, 14) and are well visualised with the MA-XRF Fe distribution maps (Fig. 4, 9), suggesting the use of ferrous 

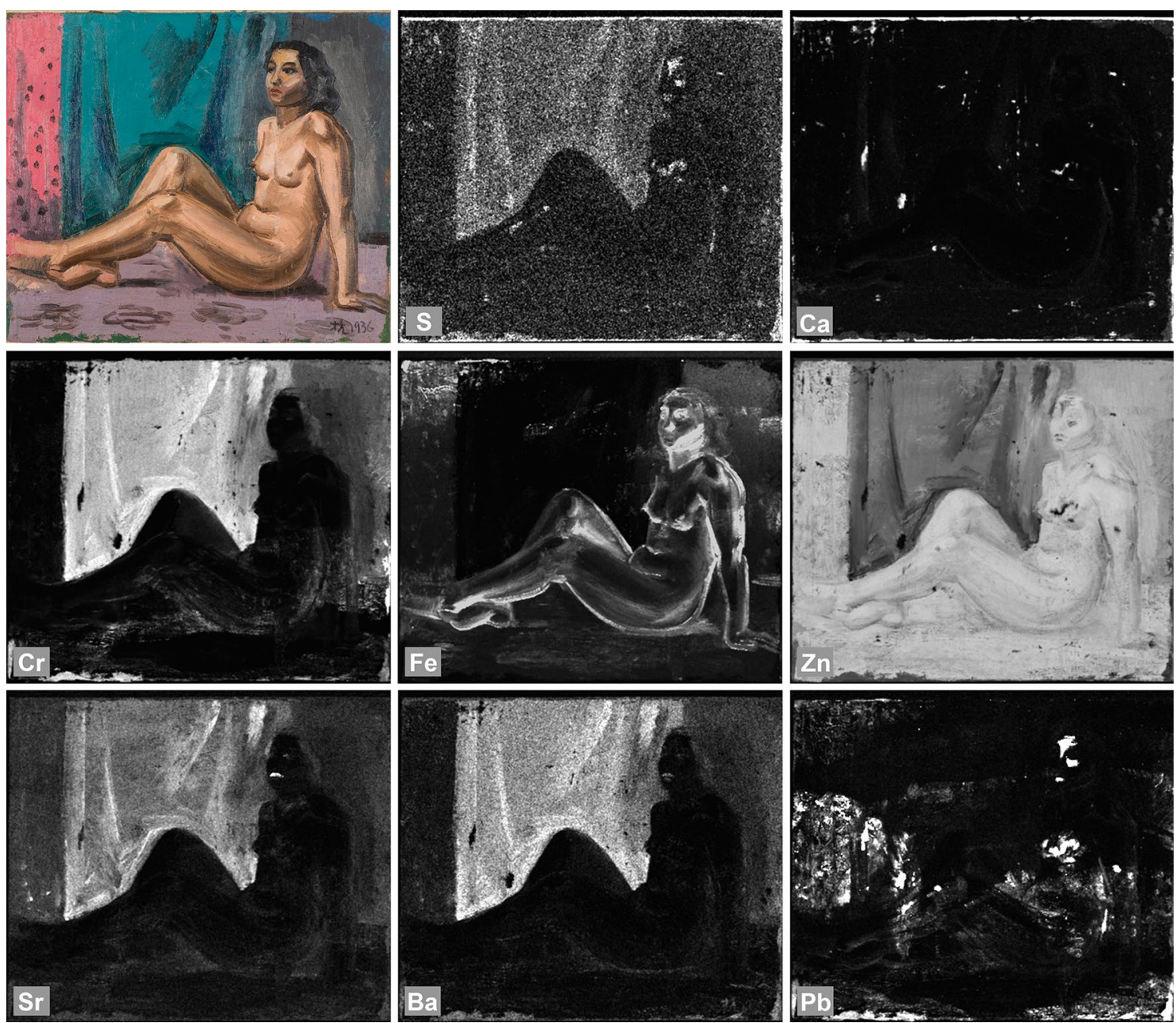

Fig. 9 Visible light image and MA-XRF maps of Nude showing the distribution of the detected elements. The greyscale corresponds to the intensity of the signal of each element: white equals high intensity, black means low intensity. The distribution map of Ca indicates areas of later conservation infills. The distribution map of $\mathrm{Pb}$ corresponds mainly to the underlying composition and its impastos recorded with RTI and XRR, except for the $\mathrm{Pb}$-signal from the model's face, which links directly with the final composition
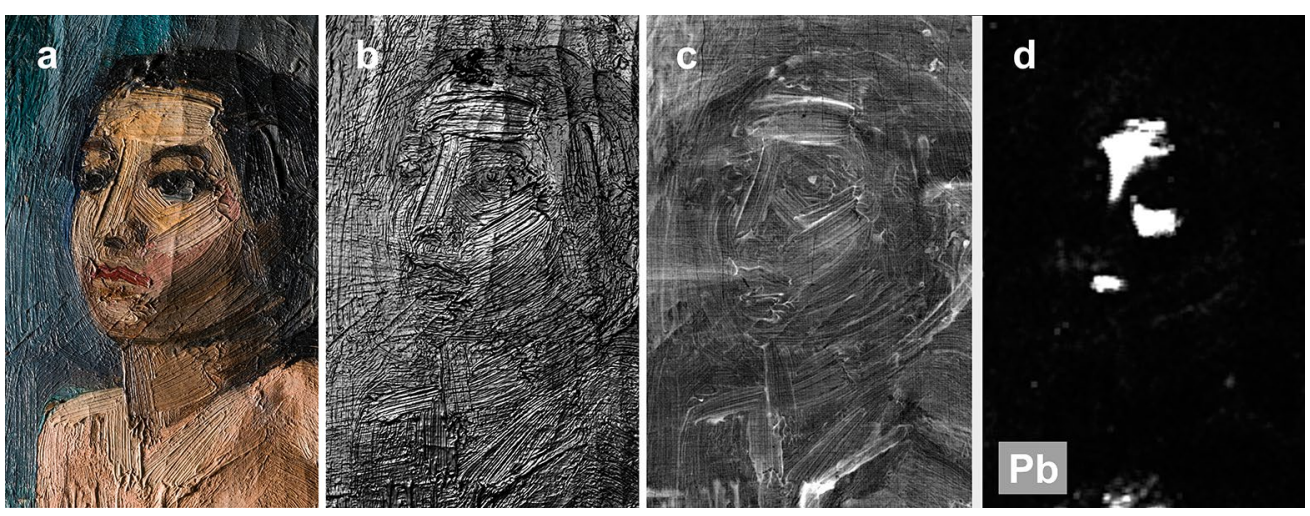

Fig. 10 Close-up of the model's face imaged by means of: a raking light photography; b RTI; c XRR; d MA-XRF Pb-distribution map. The Pb-signal from model's face does not correlate with a thick brushwork recoded with raking light photography, RTI and XRR 


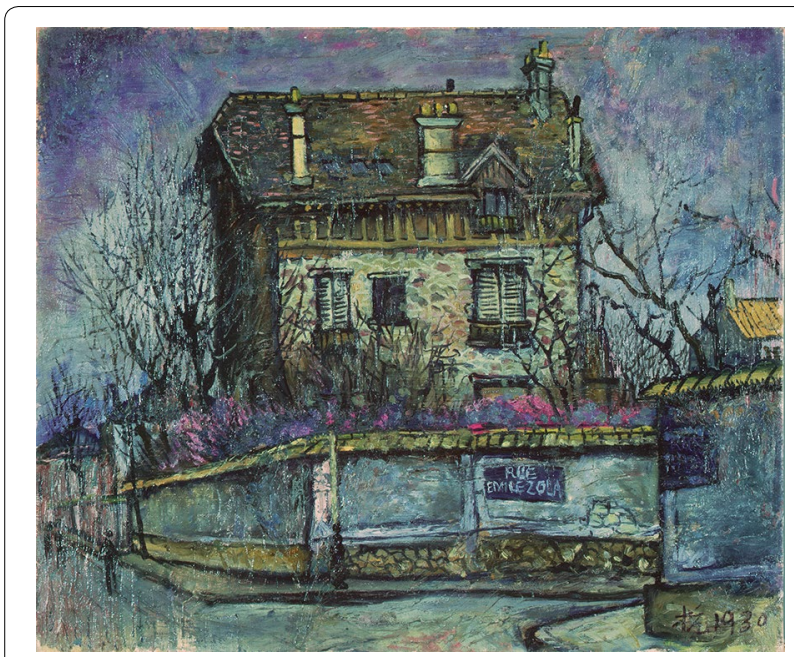

Fig. 11 Infrared false-colour image of Zuo La Lu

pigment(s). The SEM-EDS and PLM identified them as yellow and brown iron oxides. In addition, traces of As were detected with SEM-EDS in the areas with a higher concentration of $\mathrm{Fe}$, indicating a natural origin of iron oxide pigments [19]. The sources of $\mathrm{Pb}, \mathrm{Ca}$ and $\mathrm{Ba}$ are difficult to determine as these elements co-exist naturally with iron oxides [20], but together with $\mathrm{Cr}$, which is also present in the paint samples, they can make up chrome yellow, confirmed in PLM and other Cr-containing yellow pigment(s) not identified with PLM. However, it is known that ochres had been enhanced during the manufacturing process by a small addition of chrome yellow, $[18,20]$, which can also have its own extenders, such as barium white, gypsum and kaolin, and may be present in the paint samples [18]. In $Z u o L a L u$, an addition of strontium yellow is suspected in the yellow and brown paints, based on the SEM-EDS Sr-signal, while the presence of $\mathrm{Ca}$ and $\mathrm{P}$ in the brown paint may indicate the admixture of bone black. In Nude, the model's flesh tone was mainly achieved by mixing yellow iron oxide with zinc white. Traces of $\mathrm{Pb}, \mathrm{Cr}$ and $\mathrm{Sr}$ may suggest low concentration of chrome yellow and contamination with of strontium yellow. Interestingly, the MA-XRF scan (Fig. 9) reveals a strong signal from $\mathrm{Pb}$ and $\mathrm{S}$, present in the forehead, right cheek and chin, suggesting the use of a $\mathrm{Pb}$ containing paint at an earlier painting stage, and covered later by a thick application of a $\mathrm{Zn}$-containing paint.
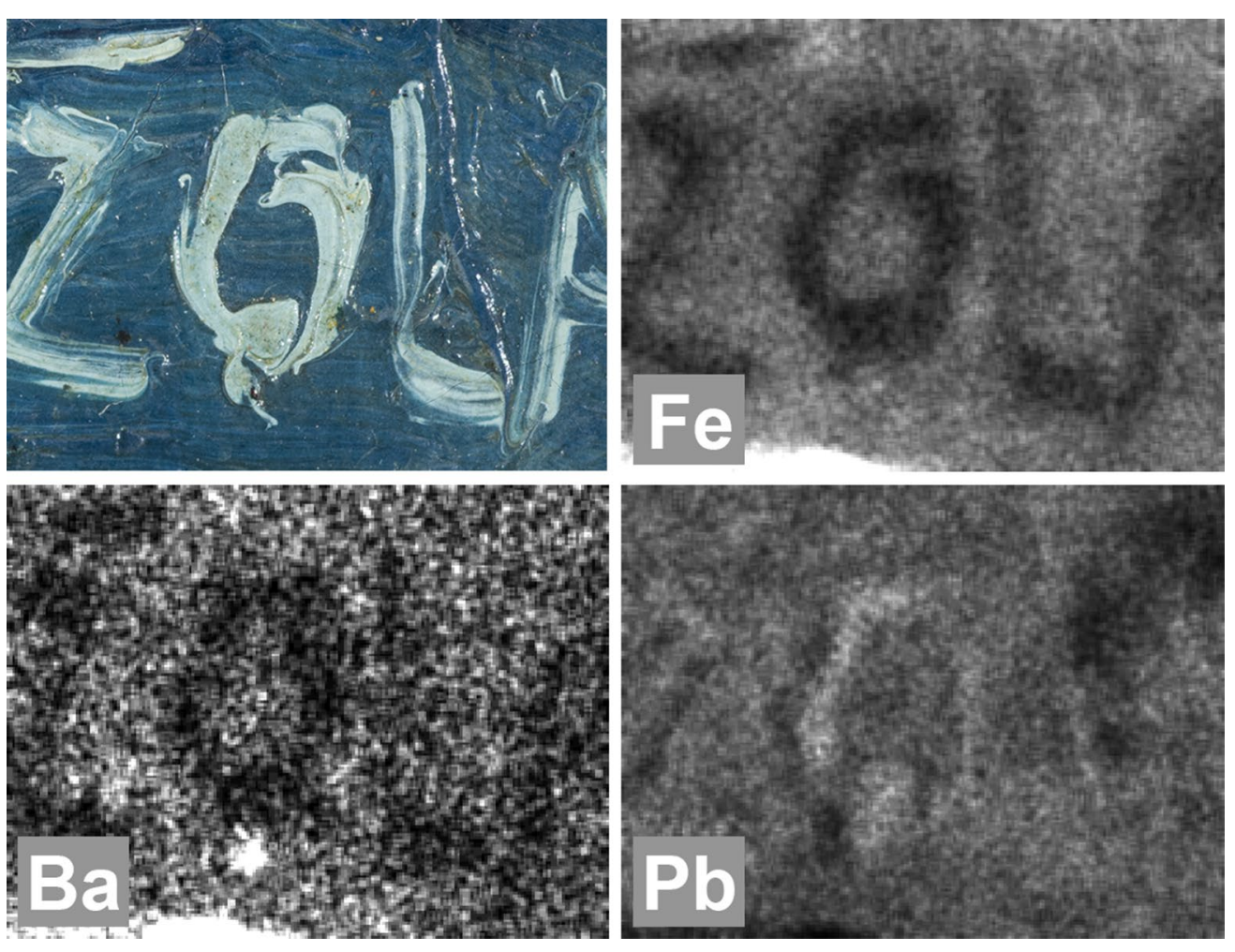

Fig. 12 Close-up of the detail of the blue street sign from Zuo La Lu and MA-XRF maps. The distribution of the three main elements, Fe, Ba, Pb, is shown. Fe-signal relates to the Prussian blue later identified with SEM-EDS and PLM. The greyscale corresponds to the intensity of the signal of each element: white equals high intensity, black means low intensity 


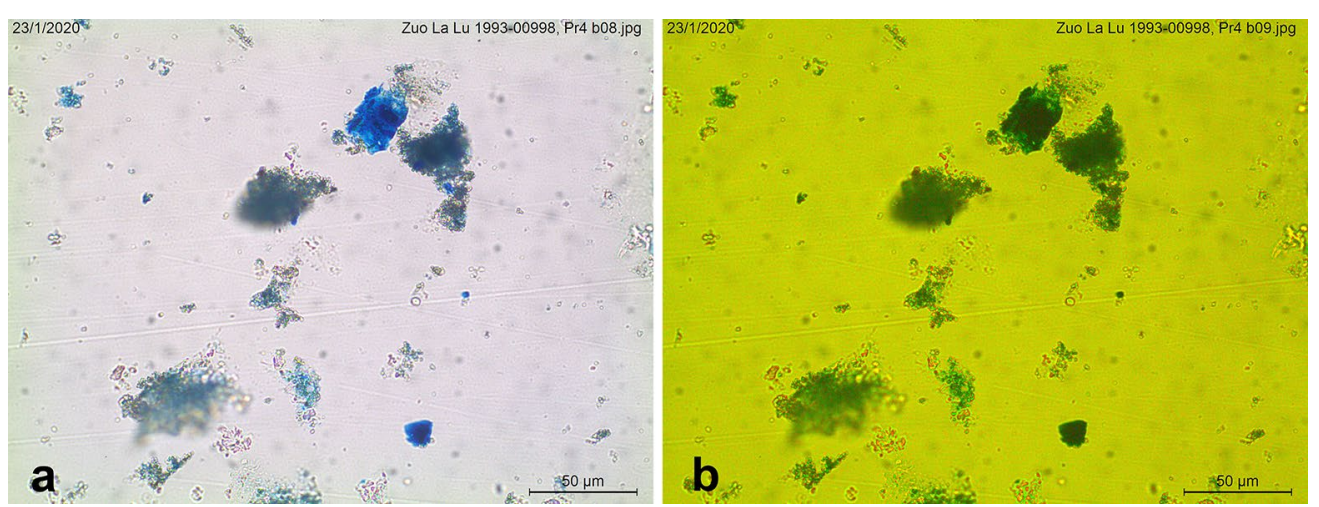

Fig. 13 Prussian blue particles from sample 4 taken from blue street sign from Zuo La Lu photographed in transmitted polarized (a) and with Chelsea filter (b)

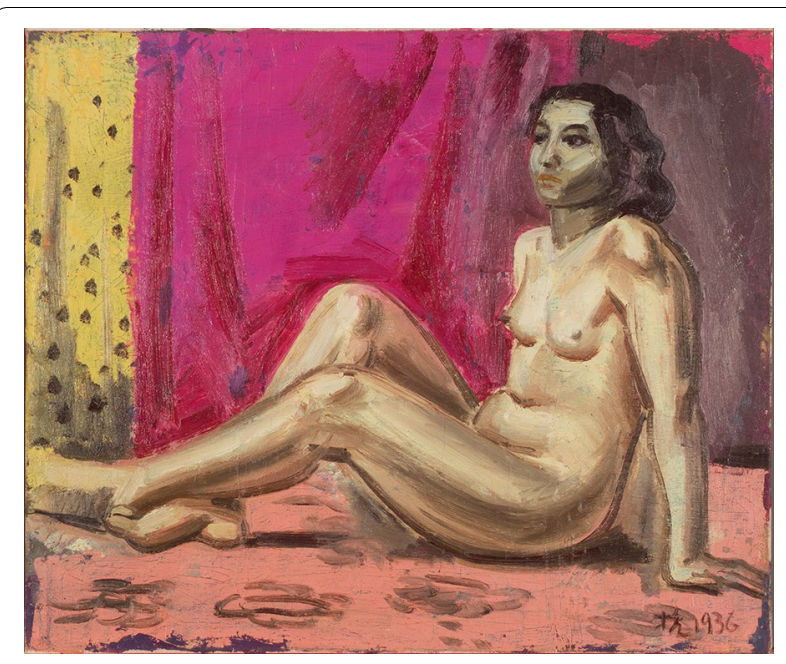

Fig. 14 Infrared false-colour image of Nude

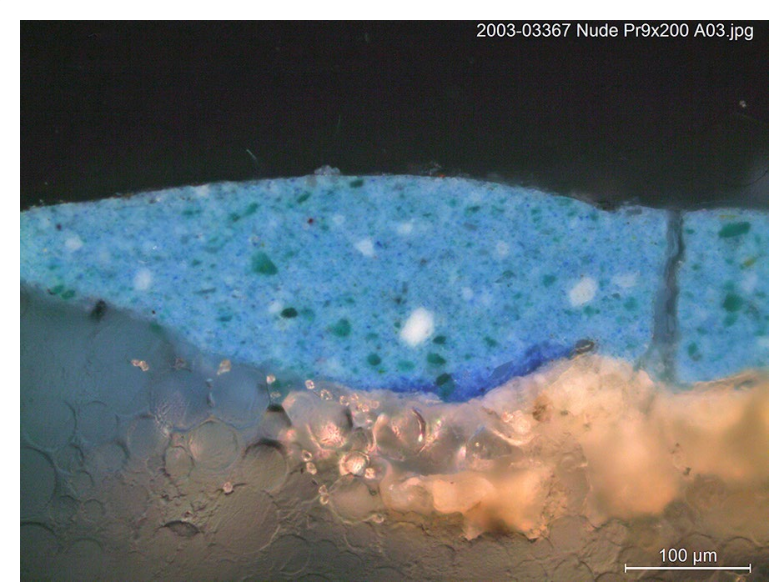

Fig. 15 Cross-section of sample 9 from Nude. The image shows that the blue paint was laid directly on the ground layer, thus suggesting that it may relate to the previous paint scheme

\section{Red and pink paints}

Red paint from the roof of the smaller house in Zuo La $L u$ probably contains a red iron oxide pigment (anisotropic and uniform red particles between polarized filters with high refractive index) with the admixture of chrome yellow. Other Cr-containing yellow pigment(s), although not identified with PLM, cannot be excluded. In Nude, red paint was used for the definition of the model's lips. Based on SEM-EDS and PLM, it is probably composed of red iron oxide, organic red, an admixture of strontium yellow and zinc white. Strong MA-XRF and SEM-EDS signals of $\mathrm{Ba}$ and $\mathrm{S}$ may suggest the presence of barium white extender for organic red.

Based on the MA-XRF, SEM-EDS and PLM analysis of the pink curtain, I deduce that the area consists mainly of several elements that could be assigned to strontium yellow, yellow iron oxide, zinc and barium whites and chrome yellow. The PLM allowed the identification of an organic red, which would be consistent with the yellow colour in the IRFC image. Although other red pigments are also imaged yellow in the IRFC, none of them was detected with the instrumental methods; nonetheless, further analyses are required to identify the red pigment.

\section{Black paints}

The black paint from the tree branches in $\mathrm{Zuo} \mathrm{La} \mathrm{Lu}$ is characterised by the strong Fe-signal recorded by MA$\mathrm{XRF}$ and SEM-EDS. The detection of Fe is usually related to both the presence of iron oxide pigments and Prussian blue, which was further identified with PLM. A presence of a small admixture of bone black is possible, based on the SEM-EDS detection of Ca- and P-signals in the paint sample and PLM observation (anisotropic grey and black particles). The additional presence of $\mathrm{Pb}, \mathrm{Ba}$ and $\mathrm{S}$ can suggest the use of lead and barium whites. 


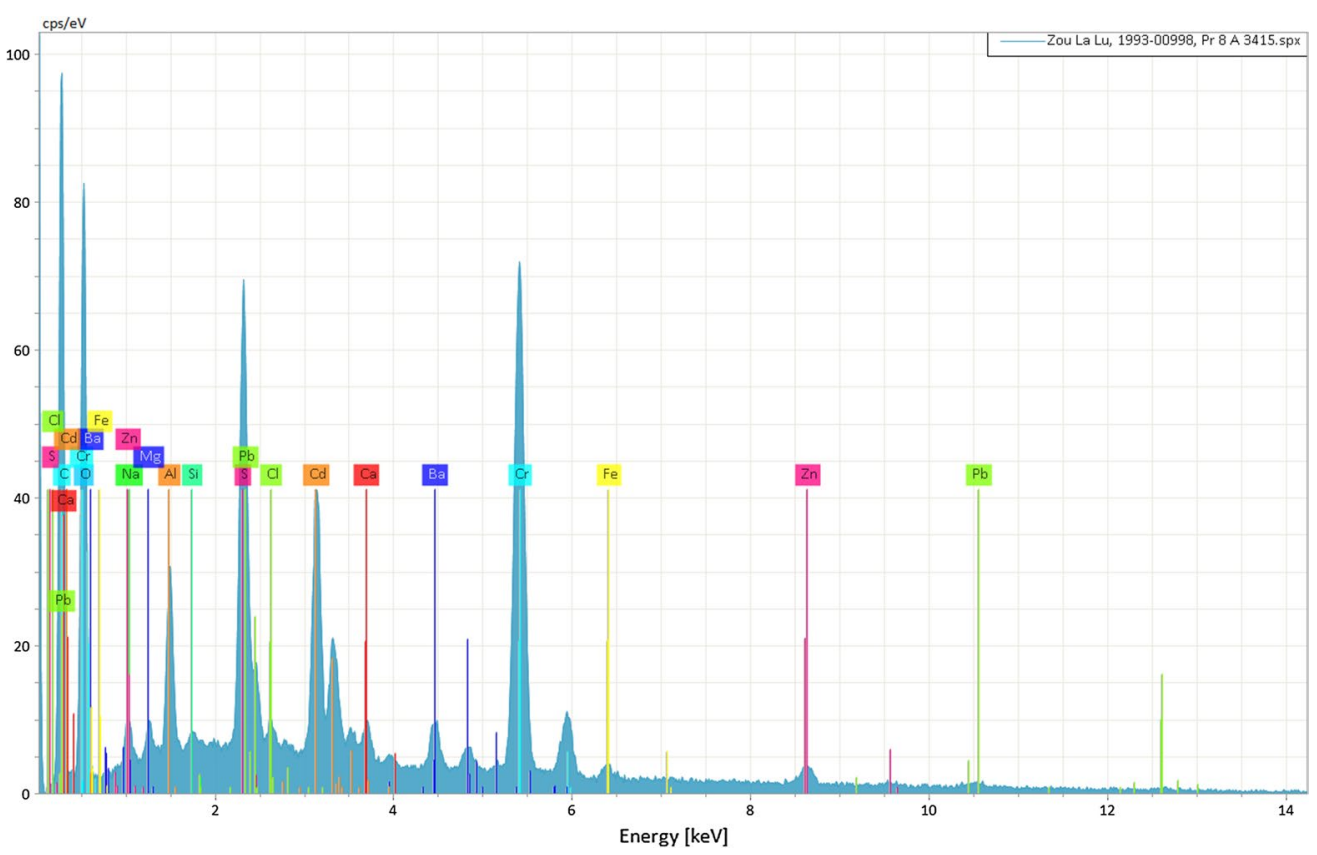

Fig. 16 SEM-EDS quantitative elemental analysis of the top green layer in sample 8 from Zuo La Lu. The spectra indicates elements that were assigned to viridian, ultramarine, Prussian blue, lead white and cadmium yellow. Cadmium yellow is characterised by strong Cd-and S-signals. The findings were correlated with PLM observations

The model's black hair in Nude is imaged black but with a warm, reddish hue in the IRFC, suggesting that the black colour was obtained by mixing several pigments. This information was found relevant with the SEM-EDS results where elements characteristic for bone black, ultramarine and viridian were detected and identified later with PLM. The yellow iron oxide-containing

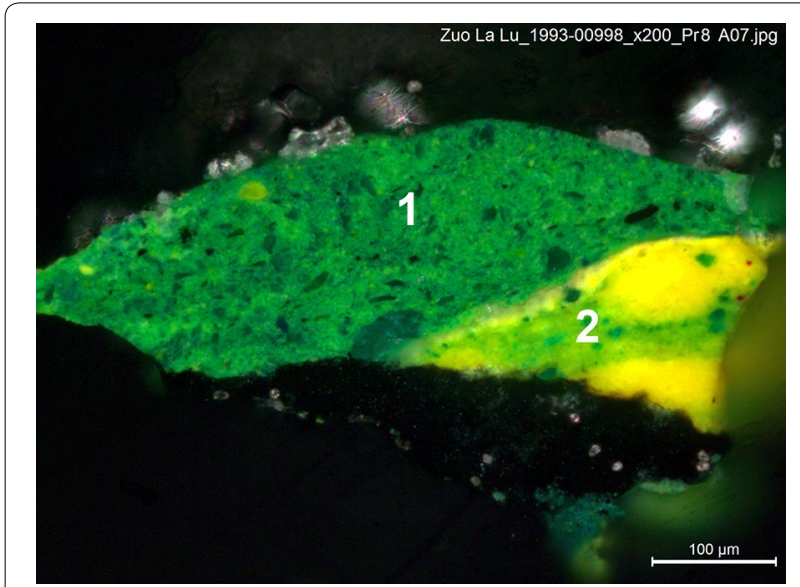

Fig. 17 Cross-section of sample 8 from Zuo La Lu. Layer 2 is characterised by clusters of green and yellow paint pigment with a possible addition of zinc and barium whites were found in the mixture as well.

\section{White paints}

In both paintings, Liu Kang did not apply a pure white paint; however, white appears in mixtures with other pigments already identified. It is quite clear that lead white is predominant in $\mathrm{Zuo} \mathrm{La} \mathrm{Lu}$ and appears in mixtures with zinc and barium whites. In Nude, the artist preferentially used zinc and barium whites; lead white appears only on the model's face and was clearly visualised with MA-XRF scanning.

\section{Conclusions}

The analytical investigations carried out in this study proved to be complementary and gave insights into the pigments used by Liu Kang in the paintings representing his two early and distinct artistic phases-Paris and Shanghai. The MA-XRF scanning provided an opportunity to visualise the distribution of elements indicative of pigments; however, it didn't allow the pigments associated with the underlying paintings to be fully characterised. Although the IRFC imaging did not provide conclusive results, it proved to be a useful tool for the tentative identification of the pigments and the selection of potential sampling areas for the SEM-EDS and 


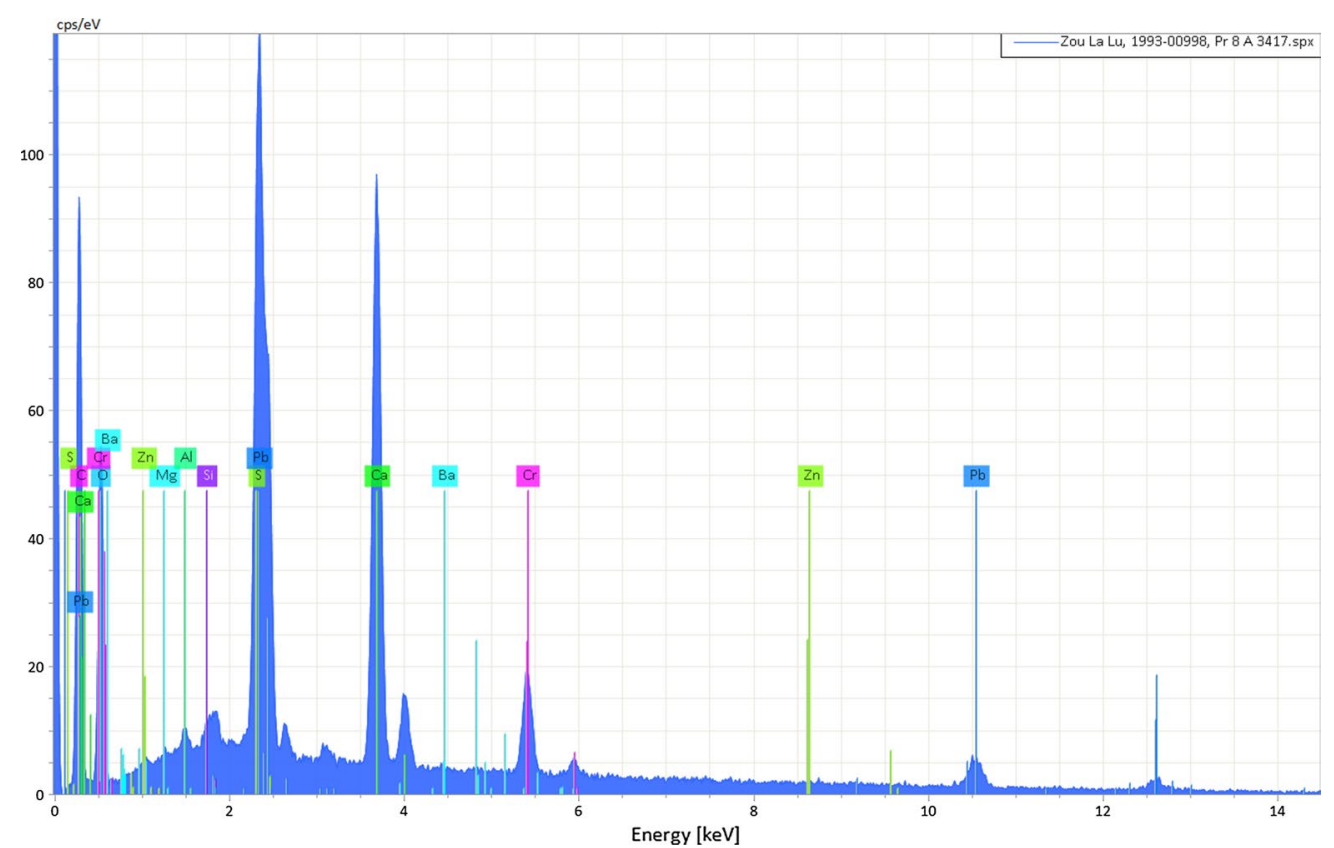

Fig. 18 SEM-EDS quantitative elemental analysis of yellow cluster in sample 8, layer 2 from Zuo La Lu. Cr-containing pigment with possible extenders can be attributed to the yellow paint

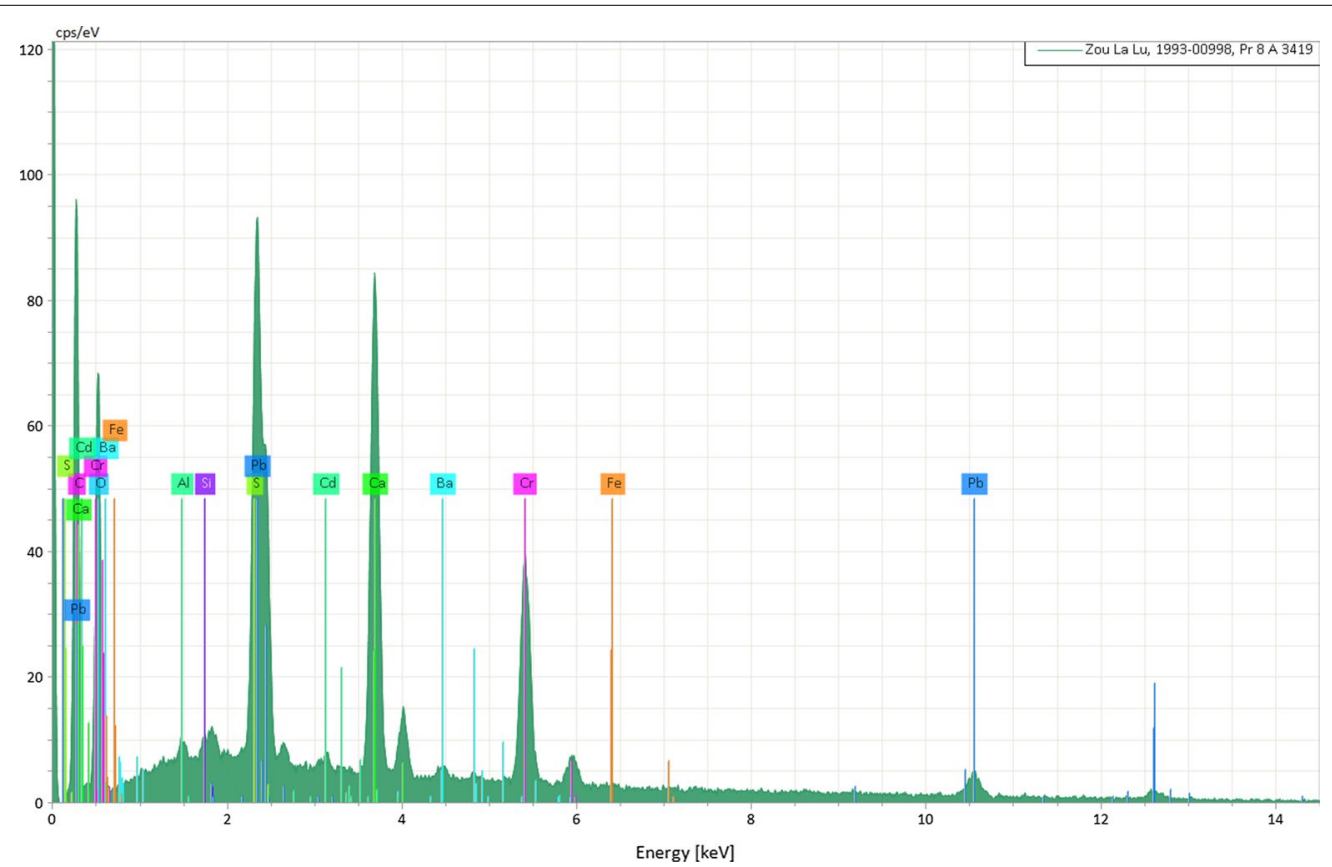

Fig. 19 SEM-EDS quantitative elemental analysis of green cluster in sample 8, layer 2 from Zuo La Lu. The green paint probably contains Cr-based green and yellow pigments with possible extenders. The weak Cd-signal indicates a trace amount of cadmium yellow

PLM [8]. The provided results show that the majority of pigments used in both paintings are similar and include Prussian blue, ultramarine, viridian, strontium yellow, chrome yellow, cadmium yellow, iron oxides (yellow, brown and red), lead, zinc and barium whites. The analytical methods also suggest the use of bone black and 

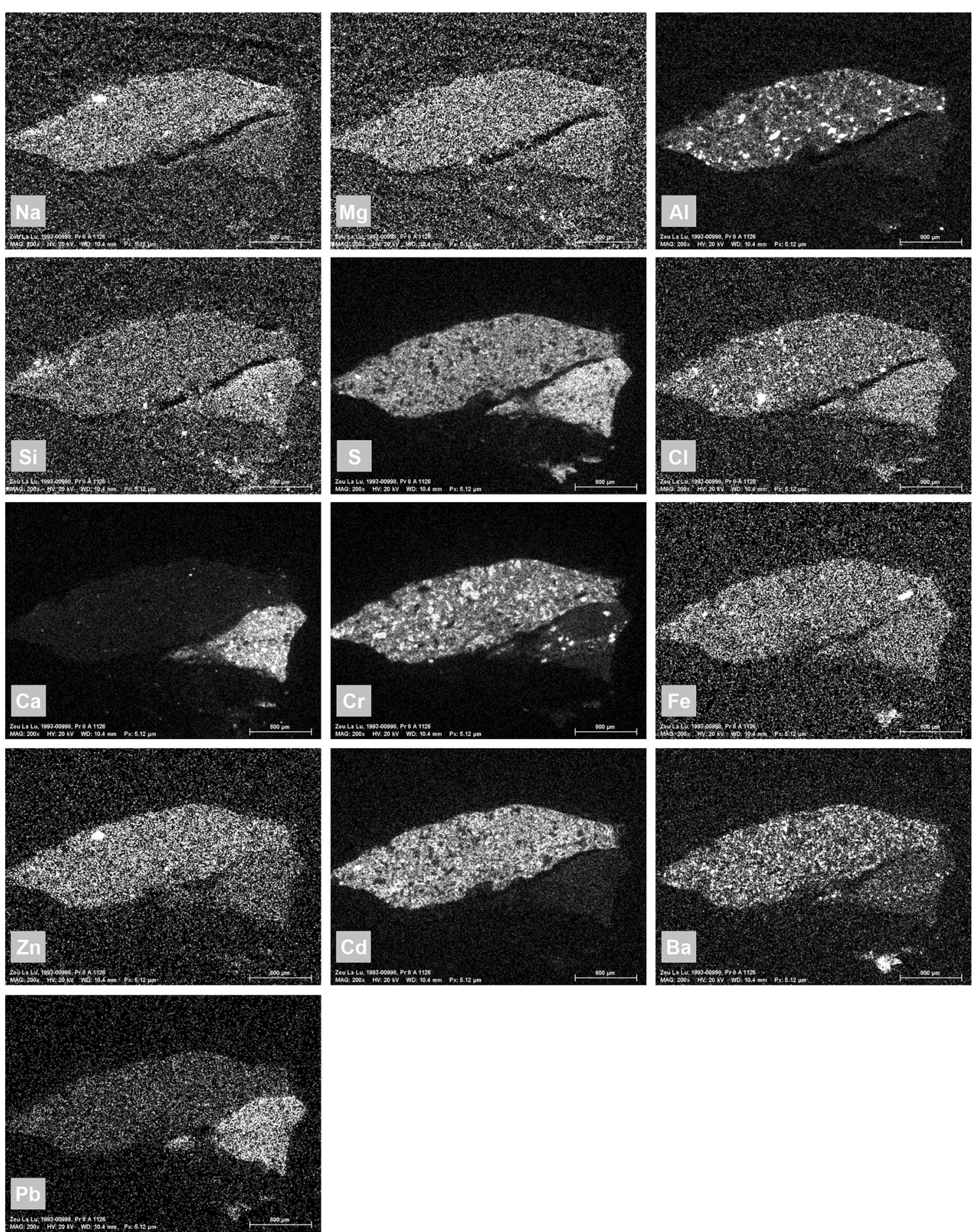

Fig. 20 SEM-EDS maps showing the distribution of the detected elements in sample 8 from Zuo La Lu. The greyscale corresponds to the intensity of the signal of each element: white equals high intensity, black means low intensity. Cadmium, which was assigned to cadmium yellow, is confined only to the upper layer while the second layer is characterised mainly by $\mathrm{Ca}, \mathrm{Pb}$ and $\mathrm{Cr}$

organic red. Particularly interesting is the predominance of lead white in $\mathrm{Zuo} \mathrm{La} \mathrm{Lu}$ while zinc white was extensively used in Nude. A comparison of the ground layers also indicates the presence of a lead white admixture in
Zuo La $\mathrm{Lu}$ while its absence in Nude may point to a characteristic difference between the two artistic phases, possibly determined by the availability of materials. 

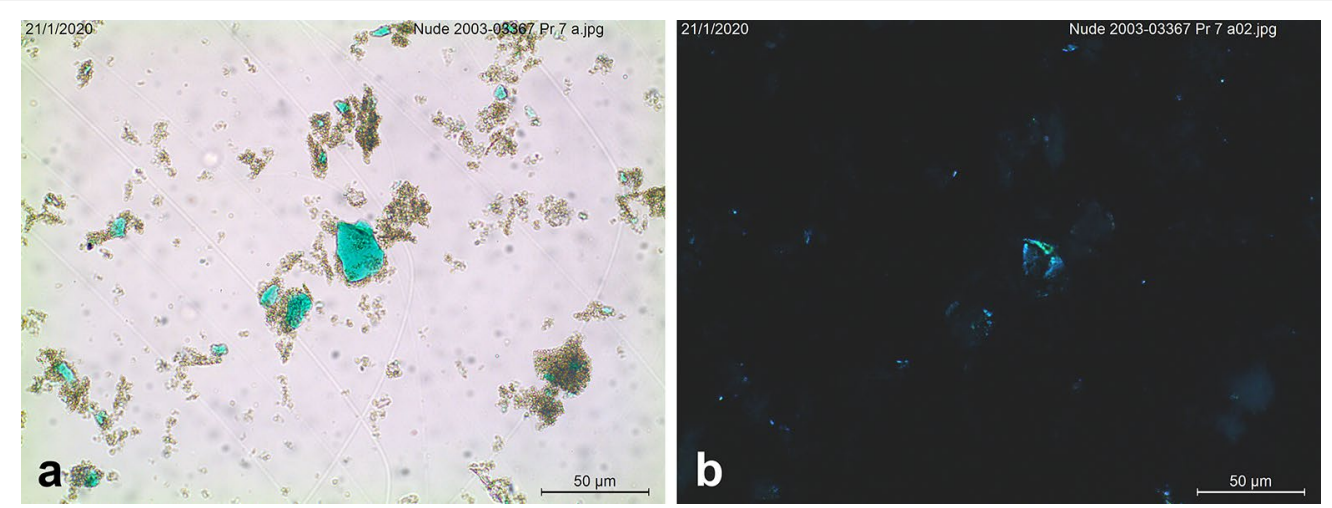

Fig. 21 Viridian particles from sample 7 taken from green curtain behind the model from Nude, photographed in transmitted polarized (a) and between crossed polars (b)

The combination of RTI, XRR and MA-XRF permitted the visualisation of the hidden canal house behind $Z u o$ $L a L u$ and allowed the detection of a discarded composition, probably an outdoor view, which was later overpainted with the final image of Nude. The details of the compositions remain unknown; however, different analytical techniques permitted the preliminary identification of some pigments used in the creation of the hidden paintings.

The interpretation of the collected data highlighted some points that require further research. These aspects include the clarification of whether, other than chrome and strontium yellow, Cr-containing yellows were used; and of the characterisation of the organic red pigment from Nude. The fragmentary presence of the Pb-containing pigment on the model's face is particularly interesting and requires further analysis to fully identify the pigment composition in this area. The revelation of the two hidden paintings creates an opportunity for further analysis to determine the composition details and the materials used. Extending the research over a broader group of paintings could determine whether the composition of the ground layers and the usage of lead white actually underwent an important transition after 1933. The identification of the canvas supports and paint binding media used for these works was beyond the scope of this study and will be addressed in the next phase of the research.

The study contributes to the knowledge on Liu Kang's painting materials and habits. The results of this study may be interesting for conservators and art historians investigating the painting materials and techniques of this artist and other artists active during the same period.

\section{Abbreviations}

UVF: Ultraviolet fluorescence; UVR: Reflected ultraviolet; NIR: Near-infrared; IRFC: Infrared false-colour; RTI: Reflectance transformation imaging; XRR: X-ray radiography; MA-XRF: Macro X-ray fluorescence; SEM-EDS: Scanning electron microscope with energy dispersive spectroscopy; OM: Optical microscopy; PLM: Polarized light microscopy.

\section{Acknowledgements}

The author is grateful to Professor Jaroslaw Rogoz PhD at Nicolaus Copernicus University for reviewing this paper; the National Gallery Singapore for allowing him to analyse the paintings; the Heritage Conservation Centre for supporting this study; Gretchen Liu for sharing the Liu Kang's family archival materials; Bruker Nano GmbH for lending the MA-XRF (M6 Jetstream) and facilitating the scanning; Kenneth Yeo Chye Whatt (Principal Radiographer from Division of Radiological Sciences of Singapore General Hospital); and Dr Steven Wong Bak Siew (Head and Senior Consultant from the Department of Radiology at Sengkang General Hospital) for facilitating the X-ray radiography; and Roger Lee (Assistant Painting Conservator from Heritage Conservation Centre) for his assistance at RTI.

\section{Authors' contributions}

$\mathrm{DL}$ carried out the examination of the paintings, using technical photography, sampling, SEM-EDS and PLM analysis; provided the interpretation of the datasets; and wrote the manuscript. The author read and approved the final manuscript.

\section{Funding}

Not applicable.

\section{Availability of data and materials}

The datasets used and/or analysed during the current study are available from the author upon request.

\section{Competing interests}

Author declares that he has no competing interests.

Received: 4 January 2020 Accepted: 5 February 2020

Published online: 22 February 2020

\section{References}

1. Liu K. Liu Kang drawn from life. Singapore: Singapore Art Museum; 2002. p. 102.

2. Kwok KC. Journeys: Liu Kang and his art =Yi cheng: Liu Kang qi ren qi yi. Singapore: National Arts Council; 2000. p. 49, 57.

3. Liu K. Western painting in Singapore in the last 45 years. In: Liu K, editor. Liu Kang: essays on art \& culture. Singapore: National Art Gallery; 2011. p. 231.

4. Sabapathy TK. Romance of art. In The Straits Times, 1981 Apr 14: Leisure 2: 5. 
5. Kolesnikov-Jessop S. Drawing the spirit of life: Liu Kang and life drawing In: Yeo WW, editor. Liu Kang: colourful modernist. Singapore: National Art Gallery; 2011. p. 98.

6. Cosentino A. Identification of pigments by multispectral imaging; a flowchart method. Herit Sci. 2014. https://doi.org/10.1186/2050-7445-2-8.

7. Cosentino A. Practical notes on ultraviolet technical photography for art examination. Conserv Património. 2015;21:53-62. https://doi. org/10.14568/cp2015006.

8. Cosentino A. Infrared technical photography for art examination. e-Preserv Sci. 2016;13:1-6.

9. Warda J. The AIC guide to digital photography and conservation documentation. Washington DC: AIC; 2011.

10. Schroer C, Bogart J, Mudge B, Lum M. Guide to highlight image capture. Cult Herit Imaging; 2013. http://culturalheritageimaging.org/What_We_ Offer/Downloads/RTI_HIt_Capture_Guide_v2_0.pdf. Accessed 9 Oct 2019.

11. Schroer C, Bogart J, Mudge B, Lum M. Guide to highlight image processing. Cult Herit Imaging; 2011. http://culturalheritageimaging.org/What_ We_Offer/Downloads/rtibuilder/RTI_hlt_Processing_Guide_v14_beta. pdf. Accessed 9 Oct 2019

12. Schroer C, Bogart J, Mudge B, Lum M. Guide to RTIViewer. Cult Herit Imaging; 2013. http://culturalheritageimaging.org/What_We_Offer/ Downloads/rtiviewer/RTIViewer_Guide_v1_1.pdf. Accessed 9 Oct 2019.

13. Matthias A, Pedroso JV, van Eikema Hommes M, Van der Snickt G, Tauber $G$, Blaas J, Haschke $M$, et al. A mobile instrument for in situ scanning macro-XRF investigation of historical paintings. J Anal At Spectrom. 2013;28(5):761-2. https://doi.org/10.1039/C3JA30341A.
14. Mactaggart P, Mactaggart A. A pigment microscopist's notebook, 7th rev. Sommerset; 1998.

15. Schalm O, Vanbiervliet L, Willems P, De Schepper P. Radiography of paintings: limitations of transmission radiography and exploration of emission radiography using phosphor imaging plates. Stud Conserv. 2014;59:1023. https://doi.org/10.1179/2047058413Y.0000000088.

16. Feller RL. Barium sulfate-natural and synthetic. In: Feller RL, editor. Artists' pigments: a handbook of their history and characteristics, vol. 1. Washington: National Gallery of Art; 1986. p. 47.

17. Fiedler I, Bayard MA. Cadmium yellows, oranges and reds. In: Feller RL, editor. Artists' pigments: a handbook of their history and characteristics, vol. 1. Washington: National Gallery of Art; 1986. p. 65.

18. Kühn H, Curran M. Chrome yellow and other chromate pigments. In: Feller RL, editor. Artists' pigments: a handbook of their history and characteristics, vol. 1. Washington: National Gallery of Art; 1986. p. 190, 196, 207, 201-7.

19. Manasse A, Mellini M. Iron (hydr)oxide nanocrystals in raw and burnt sienna pigments. Eur J Mineral. 2006;18(6):90. https://doi org/10.1127/0935-1221/2006/0018-0845.

20. Helwig K. Iron oxide pigments: natural and synthetic. In: Berrie BH, editor. Artists' pigments: a handbook of their history and characteristics, vol. 4. Washington: National Gallery of Art; 2007. p. 88, 65, 73.

\section{Publisher's Note}

Springer Nature remains neutral with regard to jurisdictional claims in published maps and institutional affiliations.

\section{Submit your manuscript to a SpringerOpen ${ }^{\odot}$ journal and benefit from:}

- Convenient online submission

- Rigorous peer review

- Open access: articles freely available online

- High visibility within the field

- Retaining the copyright to your article

Submit your next manuscript at $\boldsymbol{\nabla}$ springeropen.com 